\title{
BPR application in China of a SME Information Management Xiaobing Pei ${ }^{1, a}$, Hongyang Cha ${ }^{2, b}$ \\ ${ }^{1}$ School of Management, Tianjin University of Technology, Tianjin, 300384, China \\ acims1995@126.com, b904178210@qq.com
}

Keywords: Small business, Business management, Business Process Reengineering, Analytic hierarchy process.

\begin{abstract}
Today, science and technology, especially the rapid development of information technology, competition among enterprises, speed has become the key to the success of business development; in order to enhance the competitiveness of SMEs in China, to accelerate the development of SMEs, this article on business process reengineering of certain SMEs discussed a preliminary analysis to clarify the application of BPR in SMEs in China is not only necessary, but also feasible. On this basis, the establishment of a series of models, models such as the Analytic Hierarchy Process. For application of BPR in a quantitative analysis of SMEs, SMEs in China should be explained when and in what way, to what reengineering processes, thereby increasing scientific applications
\end{abstract}

\section{Introduction}

BPR is a long-standing management philosophy. The late $1800 \mathrm{~s}$, management theory proposed "to make the process optimal" and "recycling" thinking. Early 20th century, the reengineering Fayol defined as "to achieve a specific goal leaving the existing resource optimization activities." Mid-20th century, Dr. Deming in the promotion of total quality management (TQM), the first proposed process-oriented, study and improvement of production operations of all activity on the whole proposition. Before Process Reengineering (BPR) concept appears, the US and Japan, manufacturers have begun to use concurrent engineering, lean manufacturing, JIT production (JIT), etc., is called "the thinking process reengineering has imprinted" management techniques. In the 1980s and 1990s, the US General Electric Company at the time, led by chairman and CEO Jack Welch, the company's business processes conducted a thorough transformation, business process-centric, re-build the organizational structure, improve the company's corporate culture, so General Electric to become the world's most valuable company. The late 1990s, the implementation of the Haier Group to "market chain" as a link to the business process reengineering, enterprise competitiveness and efficiency have been greatly improved. How to improve the operational efficiency of economic activity, and how the business process reengineering is the current number of enterprises urgently need to be addressed.

\section{Points of BPR implementation}

Under the influence of the traditional division of labor, the work flow is divided into a variety of simple tasks, managers will focus on improving the efficiency of individual tasks, while ignoring the ultimate goal, namely to meet customer needs. And the implementation of BPR, the idea is to have a global, enterprise processes confirm the whole, the pursuit of global optimization, rather than individual optimal.

\section{Introduction enterprise}

South of the instrument is available in three production companies, sales and service base. Company employees more than 50 people, has eight functional departments of Finance, Production and Technology Department, Sales Department, Planning Department, Ministry of Personnel and auditing, under certain team, is a typical functions of the system's organizational structure model . 


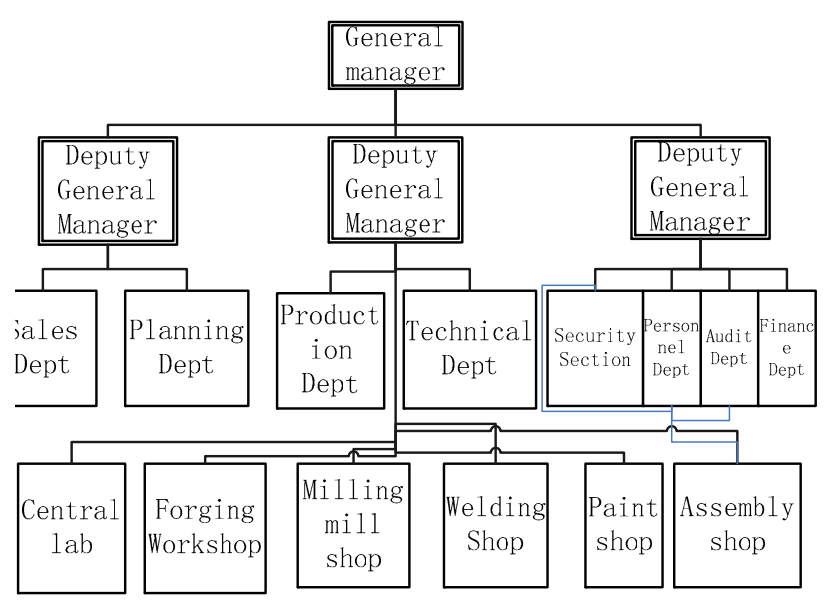

Fig. 1 Organization Chart

\section{Enterprises implementation of BPR}

In order to improve the company's management to address the company's management information systems to share resources issues, so they process information on the company's process reengineering, the following is the company's BPR implementation process:

Analysis and diagnosis process and the design of new processes. South Instrumentation Equipment Co., Ltd. decided to conduct process reengineering, and according to the size and scope of the SME processes, enterprise processes into business processes, strategic processes, assurance processes, procurement processes, research and development processes, human resource management processes and sales process other seven processes, how right it is reasonable in making? Recycling processes among priorities How? Here analytic hierarchy process to solve these problems and provide a good basis for the judgment to solve these problems: The basic steps are as follows:

(1) Analyze the relationship between the factors and establish a hierarchical structure model.

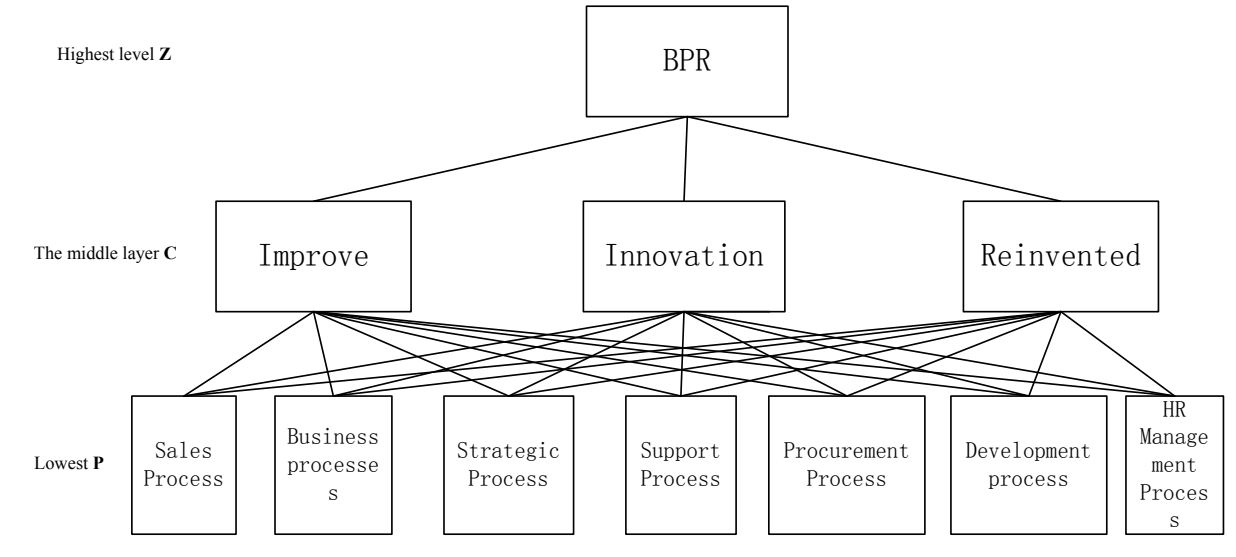

Fig. 2 BPR hierarchy chart

(2) Judgment matrix, the judgment matrix for positive and negative anti-matrix (eg: $A=\left(a_{i j}\right)_{n \times n}$, then $a_{i j}>0, a_{i j}=1 / a_{i j}, a_{i j}=1$. For convenience, the general use of this scale, Provisions with 1,3,5,7,9 elements $\mathrm{i} j$ denote the same elements, more important, important, very important, very important; $2,4,6,8$ represents the middle value $\mathrm{i} j$ element above the adjacent elements of judgment) orderC1 ExpressedImproved, C2 Expressed innovation, C3 Expressed reinvented; P1 Expressed strategy process,P2 Expressed Business processes,P3 Expressed Support Process,P4 
Expressed Procurement Process,P5 Expressed Development process,P6 Expressed HR process,P7 Expressed Infrastructure.

Judgment Matrix Z $-\mathrm{C}$
\begin{tabular}{c|ccc|l}
$Z$ & $C_{1}$ & $C_{2}$ & $C_{3}$ & $W$ \\
\hline$C_{1}$ & 1 & 5 & 3 & 0.633 \\
$C_{2}$ & $1 / 5$ & 1 & $1 / 3$ & 0.106 \\
$C_{3}$ & $1 / 3$ & 3 & 1 & 0.261
\end{tabular}

Judgment Matrix C1 - P

\begin{tabular}{c|ccccccc|c}
$C_{1}$ & $P_{1}$ & $P_{2}$ & $P_{3}$ & $P_{4}$ & $P_{5}$ & $P_{6}$ & $P_{7}$ & $W_{1}$ \\
\hline$P_{1}$ & 1 & 3 & 5 & 2 & 4 & 7 & 6 & 0.354 \\
$P_{2}$ & $1 / 3$ & 1 & 3 & $1 / 4$ & 2 & 5 & 4 & 0.151 \\
$P_{3}$ & $1 / 5$ & $1 / 3$ & 1 & $1 / 4$ & $1 / 2$ & 3 & 2 & 0.070 \\
$P_{4}$ & $1 / 2$ & 2 & 4 & 1 & 3 & 6 & 5 & 0.239 \\
$P_{5}$ & $1 / 4$ & $1 / 2$ & 2 & $1 / 3$ & 1 & 4 & 3 & 0.106 \\
$P_{6}$ & $1 / 7$ & $1 / 5$ & $1 / 3$ & $1 / 6$ & $1 / 4$ & 1 & $1 / 2$ & 0.032 \\
$P_{7}$ & $1 / 6$ & $1 / 4$ & $1 / 2$ & $1 / 5$ & $1 / 3$ & $1 / 2$ & 1 & 0.047
\end{tabular}

Judgment Matrix C2 - P

\begin{tabular}{c|ccccccc|c}
$C_{2}$ & $P_{1}$ & $P_{2}$ & $P_{3}$ & $P_{4}$ & $P_{5}$ & $P_{6}$ & $P_{7}$ & $W_{2}$ \\
\hline$P_{1}$ & 1 & 2 & 3 & 4 & 5 & 9 & 6 & 0.347 \\
$P_{2}$ & $1 / 2$ & 1 & 2 & 3 & 4 & 8 & 5 & 0.235 \\
$P_{3}$ & $1 / 3$ & $1 / 2$ & 1 & 2 & 3 & 8 & 4 & 0.161 \\
$P_{4}$ & $1 / 4$ & $1 / 3$ & $1 / 2$ & 1 & 2 & 7 & 3 & 0.109 \\
$P_{5}$ & $1 / 5$ & $1 / 4$ & $1 / 3$ & $1 / 2$ & 1 & 6 & 2 & 0.074 \\
$P_{6}$ & $1 / 9$ & $1 / 8$ & $1 / 8$ & $1 / 7$ & $1 / 6$ & 1 & $1 / 5$ & 0.021 \\
$P_{7}$ & $1 / 6$ & $1 / 5$ & $1 / 4$ & $1 / 3$ & $1 / 2$ & 5 & 1 & 0.053
\end{tabular}

Judgment Matrix C3- $\mathrm{P}$

\begin{tabular}{c|ccccccc|c}
$C_{3}$ & $P_{1}$ & $P_{2}$ & $P_{3}$ & $P_{4}$ & $P_{5}$ & $P_{6}$ & $P_{7}$ & $W_{3}$ \\
\hline$P_{1}$ & 1 & 6 & 8 & 5 & 2 & 7 & 8 & 0.389 \\
$P_{2}$ & $1 / 6$ & 1 & 4 & $1 / 2$ & $1 / 5$ & 2 & 3 & 0.083 \\
$P_{3}$ & $1 / 8$ & $1 / 4$ & 1 & $1 / 5$ & $1 / 8$ & $1 / 3$ & $1 / 2$ & 0.027 \\
$P_{4}$ & $1 / 5$ & 2 & 5 & 1 & $1 / 4$ & 3 & 4 & 0.121 \\
$P_{5}$ & $1 / 2$ & 5 & 8 & 4 & 1 & 6 & 7 & 0.286 \\
$P_{6}$ & $1 / 7$ & $1 / 2$ & 3 & $1 / 3$ & $1 / 6$ & 1 & 2 & 0.056 \\
$P_{7}$ & $1 / 8$ & $1 / 3$ & 2 & $1 / 4$ & $1 / 7$ & $1 / 2$ & 1 & 0.038
\end{tabular}

Were obtained for the above-mentioned judgment matrix largest characteristic $\operatorname{root} \lambda_{\max }$,Eigenvectors, consistency index $C_{I}$, Random consistency ratioCR. The algorithm is as follows: 
Step 1: The matrix is normalized by column: $b_{i j}=a_{i j} / \sum a_{i j}$;

Step 2: Press line seeking Total: $v_{i}=\sum_{j}^{i} b_{i j}$;

Step 3: $\quad w_{i}=v_{i} / \sum v_{i} \quad \mathrm{i}=1,2,3, \cdots \cdots, \mathrm{n}$

Step 4: Judgment matrix calculation maximum characteristic $\operatorname{root} \lambda_{\max }$,

$\lambda_{\max }=\frac{1}{n} \sum_{i}\left(\frac{(A W)_{i}}{w_{i}}\right)$.

Step 5: Calculated $C_{I}, C_{I}=\left(\lambda_{\max }-n\right) /(n-1)$.

Step 6: Seek Random Consistency Index $R_{I}, R_{I}$ Can generally be obtained by look-up table.

Table 1 Mean Random Consistency Index

\begin{tabular}{|c|c|c|c|c|c|c|c|l|l|}
\hline order & 3 & 4 & 5 & 6 & 7 & 8 & 9 & 10 & 11 \\
\hline RI & 0.52 & 0.89 & 1.12 & 1.26 & 1.36 & 1.41 & 1.46 & 1.49 & 1.52 \\
\hline
\end{tabular}

Step 7: Seeking consistency ratio $C_{R}, C_{R}=C_{I} / R_{I}$.

when $C_{R}<0.1$,Judgment matrix has satisfactory consistency, otherwise you will need to re-adjust the judgment matrix, so that it has satisfied until consistency.More than four judgment matrix calculation results are as follows:

Judgment Matrix Z-C

According 3-1、3-2、3-3 Obtained:

$$
B=\left[\begin{array}{lll}
0.652 & 0.556 & 0.692 \\
0.130 & 0.111 & 0.077 \\
0.218 & 0.333 & 0.231
\end{array}\right] \quad V=\left[\begin{array}{l}
1.900 \\
0.318 \\
0.782
\end{array}\right] \quad W=\left[\begin{array}{l}
0.633 \\
0.106 \\
0.261
\end{array}\right]
$$

According to the above results are substituted into the formula 4、5 Obtained: $\lambda_{\max }=3.037, C_{I}=$ 0. 0185; Look-up table $R_{I}=0.52$. According 6: Consistency ratio $C_{R}=\frac{0.0185}{0.52}=0.036, C_{R}<0.1$ So the consistency of judgment matrix is acceptable.

Judgment Matrix C1-P

According 1 2 2 3 obtained $B=\left[\begin{array}{ccccccc}0.386 & 0.412 & 0.316 & 0.476 & 0.361 & 0.250 & 0.279 \\ 0.129 & 0.137 & 0.189 & 0.060 & 0.180 & 0.179 & 0.186 \\ 0.077 & 0.046 & 0.063 & 0.060 & 0.045 & 0.107 & 0.093 \\ 0.193 & 0.275 & 0.253 & 0.238 & 0.271 & 0.214 & 0.233 \\ 0.096 & 0.069 & 0.126 & 0.079 & 0.090 & 0.143 & 0.140 \\ 0.055 & 0.027 & 0.021 & 0.040 & 0.023 & 0.036 & 0.023 \\ 0.064 & 0.034 & 0.032 & 0.048 & 0.030 & 0.071 & 0.047\end{array}\right]$

$V=\left[\begin{array}{l}2.480 \\ 1.060 \\ 0.491 \\ 1.676 \\ 0.743 \\ 0.225 \\ 0.326\end{array}\right] \quad W=\left[\begin{array}{c}0.354 \\ 0.151 \\ 0.070 \\ 0.239 \\ 0.106 \\ 0.032 \\ 0.047\end{array}\right]$ 
According to the above results are substituted into the formula 4,5 obtained: $\lambda_{\max }=7.145, C_{I}=$ 0.024 ; look up table $R_{I}=1.36$. So by the formula 6: Consistency ratio $C_{R}=\frac{0.024}{1.36}=0.018, C_{R}\langle 0.1$ So the consistency of judgment matrix is acceptable.

Judgment Matrix C2-P According 1、2、3 obtained

$B=\left[\begin{array}{lllllll}0.390 & 0.454 & 0.416 & 0.364 & 0.319 & 0.205 & 0.283 \\ 0.195 & 0.227 & 0.277 & 0.273 & 0.255 & 0.182 & 0.236 \\ 0.130 & 0.113 & 0.139 & 0.182 & 0.191 & 0.182 & 0.189 \\ 0.098 & 0.076 & 0.069 & 0.091 & 0.128 & 0.159 & 0.142 \\ 0.078 & 0.057 & 0.046 & 0.046 & 0.064 & 0.136 & 0.094 \\ 0.043 & 0.028 & 0.017 & 0.013 & 0.011 & 0.023 & 0.009 \\ 0.065 & 0.045 & 0.035 & 0.030 & 0.032 & 0.114 & 0.047\end{array}\right]$

$$
V=\left[\begin{array}{l}
2.431 \\
1.646 \\
1.127 \\
0.762 \\
0.521 \\
0.145 \\
0.368
\end{array}\right]
$$$$
W=\left[\begin{array}{l}
0.347 \\
0.235 \\
0.161 \\
0.109 \\
0.047 \\
0.021 \\
0.053
\end{array}\right]
$$

According to the above results are substituted into the formula 4,5 obtained: $\lambda_{\max }=7.361, C_{I}=0.060$; look up table $R_{I}=1.36$. So by the formula : Consistency ratio $C_{R}=\frac{0.060}{1.36}=0.044, C_{R}<0.1$ So the consistency of judgment matrix is acceptable.

\section{Judgment Matrix C3-P}

According 3-1、3-2、3-3 obtained

$$
B=\left[\begin{array}{lllllll}
0.443 & 0.398 & 0.258 & 0.443 & 0.515 & 0.353 & 0.314 \\
0.074 & 0.066 & 0.129 & 0.044 & 0.051 & 0.101 & 0.118 \\
0.055 & 0.017 & 0.032 & 0.018 & 0.032 & 0.017 & 0.020 \\
0.089 & 0.133 & 0.161 & 0.089 & 0.064 & 0.151 & 0.157 \\
0.221 & 0.331 & 0.258 & 0.335 & 0.257 & 0.303 & 0.275 \\
0.063 & 0.033 & 0.097 & 0.030 & 0.043 & 0.050 & 0.078 \\
0.055 & 0.022 & 0.065 & 0.022 & 0.037 & 0.025 & 0.039
\end{array}\right] \quad V=\left[\begin{array}{l}
2.723 \\
0.583 \\
0.190 \\
0.844 \\
2.000 \\
0.394 \\
0.265
\end{array}\right] \quad W=\left[\begin{array}{l}
0.389 \\
0.083 \\
0.027 \\
0.121 \\
0.286 \\
0.056 \\
0.038
\end{array}\right]
$$

According to the above results are substituted into the formula 2、5obtained : $\lambda_{\max }=7.323, C_{I}=$ 0.054; look up table $R_{I}=1.36$. So by the formula 6 :

$C_{R}<0.1$ Consistency ratio $C_{R}=\frac{0.054}{1.36}=0.040$ (3) As shown in Table 2 establish the lowest $\mathrm{P}$ level on the highest level of total sort Z.

Table 3-2 level ranking table

\begin{tabular}{ccccc}
\hline Lowest & $\mathrm{C}_{1}$ & $\mathrm{C}_{2}$ & $\mathrm{C}_{3}$ & $\begin{array}{c}\text { Sort levels of } \\
\text { total P }\end{array}$ \\
& 0.633 & 0.106 & 0.261 & \\
$\mathrm{P}_{1}$ & 0.354 & 0.347 & 0.389 & 0.362 \\
$\mathrm{P}_{2}$ & 0.151 & 0.235 & 0.083 & 0.142 \\
$\mathrm{P}_{3}$ & 0.070 & 0.161 & 0.027 & 0.083 \\
$\mathrm{P}_{4}$ & 0.239 & 0.109 & 0.121 & 0.132 \\
$\mathrm{P}_{5}$ & 0.106 & 0.047 & 0.286 & 0.147 \\
$\mathrm{P}_{6}$ & 0.032 & 0.021 & 0.056 & 0.097 \\
$\mathrm{P}_{7}$ & 0.047 & 0.053 & 0.038 & 0.045 \\
\hline
\end{tabular}

(4) Total Sort consistency test,

$$
C_{R}=\frac{\sum w_{j} C_{I J}}{\sum w_{j} R_{I J}}
$$


(Note the formula 3-7 $\sum$ is $\sum_{j=1}^{3}$ ).

Were always sort consistency test $P_{i}=\sum w_{j} w_{i j}$, Sort results total level $\mathrm{P}$ The values in the above table 3-2.Therefore, from the above data into the formula 7 obtained $C_{R}=0.054 . C_{R}\langle 0.1$ Sort the results have always considered satisfactory consistency, The total level of the sort from $\sum w_{j} w_{i j}$ The value of the size comparison,Draw more than seven processes relative priorities are: business processes, development processes, strategic processes, procurement processes, human resource management processes, assurance processes, sales process. So companies can make the appropriate recycling according to data provided by the AHP of these processes.

\section{Enterprises BPR effect analysis}

The company processes each new use of modern information technology and advanced management tools, a large number of complex computer systems work to do, for enterprises to save a lot of manpower and material resources. According to preliminary estimates, the reconstruction results mainly in:

Through restructuring of the old, unreasonable management system to clean up 2.Business discarded many of the original inefficient processing means, so that the data processing system to achieve the high degree of unity in the logistics, capital flow, information flow aspects:1enhanced sense of responsibility and teamwork of staff 2.Reduce management costs

BPR implementation process Problems. 1.Reengineering strategic goals are not clear, there is only one target is difficult, according to the qualitative evaluation of the success of the entire project.

2.Reengineering team composed mainly of company leaders, the problems they have to deal with a lot, not to concentrate all for recycling. The best leaders set a fixed full-time staff responsible for the organization of specialized process group. Mechanism for the formation of the whole enterprise production and management system and a variety of processes for planning, design, evaluation, improvement and innovation.

\section{Further problems}

1. Accurately grasp the needs of customers, so that customers are also added to the process.

2. Strengthen the training of staff to meet the needs to establish a new organization. According reengineering theory, after reconstruction, the basic structural unit of the formation of the new organization is the process group, whose members must be a complex process group of professionals in order to meet the needs of the new process.

\section{Summary}

BPR provides us with a new mode of thinking, that is, to break through the restrictions of various boxed, with the development of modern science and technology, creative thinking, often receive unexpected results

\section{References}

[1] J. Yu. reengineering: the reorganization of business processes. Guangzhou: Guangzhou Economic Publishing House, 2000.

[2] James Champy business reengineering X .Beijing: CITIC Publishing House, 2002.

[3] Gan Huaming Business Process. Beijing: China International Broadcasting Press, 2002(In Chinese) 
[4] Lin Chuan Khan SME development and innovation. Shanghai: Shanghai University of Finance and Economics Press, 2001(In Chinese)

[5] Z.C. Yao China Enterprise Reform and Development Case. Beijing: Economic Management Press, 2000.

[6] Baoping .BPR Analysis of SMEs in the application. Industrial Engineering, 2005.6 (In Chinese) 